\title{
Ammonia Sensing by PANI-DBSA Based Gas Sensor Exploiting Kelvin Probe Technique
}

\author{
Anju Yadav, ${ }^{1,2,3}$ Ajay Agarwal, ${ }^{1,2}$ Pankaj B. Agarwal, ${ }^{1,2}$ and Parveen Saini ${ }^{2,3}$ \\ ${ }^{1}$ CSIR-Central Electronics Engineering Research Institute, Pilani 333 031, India \\ ${ }^{2}$ Academy of Scientific \& Innovative Research (AcSIR), New Delhi 110 012, India \\ ${ }^{3}$ Polymeric and Soft Materials Section, CSIR-National Physical Laboratory, New Delhi 110 012, India
}

Correspondence should be addressed to Parveen Saini; pksaini@nplindia.org

Received 8 June 2015; Accepted 25 October 2015

Academic Editor: Raphael Schneider

Copyright (C) 2015 Anju Yadav et al. This is an open access article distributed under the Creative Commons Attribution License, which permits unrestricted use, distribution, and reproduction in any medium, provided the original work is properly cited.

\begin{abstract}
Dodecyl benzene sulfonic acid (DBSA) doped polyaniline (PANI-DBSA) has been synthesized by chemical oxidative polymerization of aniline monomer in the presence of DBSA. The UV-visible spectroscopy and X-ray diffraction measurements confirm the formation of PANI and its doping by DBSA. SEM images show the formation of submicron size rod shaped PANI particles. A vibrating capacitor based ammonia gas sensor was prepared by spin coating PANI-DBSA film over copper $(\mathrm{Cu})$ substrate. The sensor exploited Kelvin probe technique to monitor contact potential difference between PANI and $\mathrm{Cu}$ as a function of time and ammonia concentration. Upon exposure to $30 \mathrm{ppm}$ ammonia, the sensor displays response time of $329 \mathrm{~s}$, recovery time of $3600 \mathrm{~s}$, and sensitivity value of 1.54 along with good repeatability.
\end{abstract}

\section{Introduction}

Ammonia has vast applicability like use in agricultural sector, chemical industries, medicinal fields, refrigeration systems, and so forth [1-4]. However, due to its toxic nature, application of ammonia also contributes to air pollution. The hazardous effect of ammonia can be felt around few hundred ppm gas concentration [5]. Its pungent odor and irritation effect start to affect the human beings below $50 \mathrm{ppm}$ level $[2,6,7]$. Therefore, there is a need for the development of ammonia gas sensor for timely detection of ppm level concentrations of ammonia.

In the past, metal oxides based ammonia gas sensors have been developed with fast response and high sensitivity $[8,9]$. However, they have disadvantages like complex fabrication steps, high power consumption, high temperature operation, and so forth $[7,10,11]$. In this context, conjugated polymers and their nanocomposites have shown great promise as gas sensing material due to advantages in terms of facile synthesis; tunable electrical and optoelectronic properties; processing via solution route; good sensitivity of their thin film based sensor towards a number of acidic/basic gases; improved response, recovery, and sensitivity and, most importantly, room temperature operation [7, 12-17]. Among various conducting polymers, polyaniline (PANI) is considered the most promising material for gas sensing purpose, due to its low monomer cost, lab scale synthesis via chemical route, and flexibility in tuning of electrical properties, particle morphology, environmental/thermal stability, and processability via selection of dopant and adjustment of oxidation level $[7,12,18,19]$. In particular, its ability to undergo nonredox doping via protonic acid dopants and undoping by base in reversible manner makes PANI an ideal candidate for sensing of a number of toxic gases having acidic/basic character or electron donating/accepting nature [7].

In the past, a number of papers reported the formation of PANI film based gas sensor that exploited change in resistance, optical property, resonance frequency, or contact potential difference (CPD) in response to ammonia gas or vapor $[7,10,11,20,21]$. However, there is no detailed report on the PANI based ammonia sensor that measures gas exposure actuated changes in CPD between PANI layer and metallic substrate. The CPD technique is considered advantageous as there is no requirement of electrical contacts, wire bonding, or complicated fabrication steps [22]. 
This paper elaborates dodecyl benzene sulfonic acid (DBSA) doped PANI film based ammonia gas sensor, which measures change in work function of the PANI film upon exposure to ammonia. The elongated PANI-DBSA particles are prepared by oxidative polymerization and the formation of PANI and its existence in doped emeraldine salt (ES) form are ascertained by X-ray diffraction (XRD) and UV-visible spectroscopy. The morphology of PANI-DBSA is observed using scanning electron microscopy (SEM). A sensing system is formed by deposition of a layer of PANI-DBSA over copper $(\mathrm{Cu})$ substrate and the time dependent change in $\mathrm{CPD}$ between PANI and $\mathrm{Cu}$ is measured by Kelvin Probe for exposure to a given ammonia concentration. The sensor is tested for detection of ppm level concentration of ammonia gas and its sensing parameters (e.g., response time, recovery time, and sensitivity) are measured.

Materials Used. Aniline (Loba Chemie) was freshly double distilled before use. Ammonium persulfate (APS, $\left.\left(\mathrm{NH}_{4}\right)_{2} \mathrm{~S}_{2} \mathrm{O}_{8}\right)$, dodecyl benzene sulfonic acid (DBSA) (Acros), chloroform (Merck), and propanol (Merck) were used on as-received basis. Deionized water (resistivity > $\left.10^{6} \Omega-\mathrm{cm}\right)$ was used for synthesis and washing.

Synthesis of DBSA Doped Polyaniline. DBSA doped PANI (i.e., PANI-DBSA) has been synthesized by chemical oxidative polymerization of aniline monomer via direct doping route using DBSA as dopant [23, 24]. The 0.1-mole aniline monomer was mixed with $0.3 \mathrm{M}$ aqueous DBSA solution and the mixture was cooled to $0^{\circ} \mathrm{C}$. Polymerization was initiated by the dropwise addition of aqueous solution of ammonium persulfate $(0.1 \mathrm{~mol}$ in $100 \mathrm{~mL}$ deionized water $)$ to reaction mixture and maintaining reaction mixture at $0^{\circ} \mathrm{C}$ under continuous stirring. After completion of polymerization, the formed dark green emulsion of DBSA doped PANI was deemulsified using propanol. The resultant mixture was filtered through sintered glass crucible and the precipitate so obtained was washed repeatedly till the $\mathrm{pH}$ of the filtrate became neutral. Subsequently, the filtered cake was dried and crushed to obtain PANI-DBSA powder. In the next step, a calculated amount of PANI-BDSA was dispersed in chloroform by sonication followed by filtration through Whatman 41 filter paper. The filtered PANI-DBSA/chloroform dispersion layer (Figure 1) was formed over copper substrate $(8 \mathrm{~mm} *$ $8 \mathrm{~mm}$ ) by spin coating at $1000 \mathrm{rpm}$.

Characterization. The optical spectra of the chloroform dispersion of PANI-DBSA were recorded using UV-visible spectrophotometer (Perkin Elmer lambda 25) in the wavelength range of 250-1000 $\mathrm{nm}$. X-ray diffraction (XRD) pattern was recorded using Bruker Advance D8 system in the diffraction

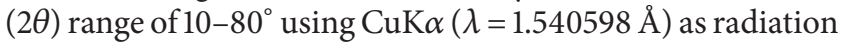
source. The scanning electron microscope (SEM, Leo-440, Carl-Zeiss, UK, accelerating potential $10.0 \mathrm{kV}$ ) was used to investigate the surface morphology of PANI-DBSA powder. The gas sensor characteristics were recorded using a Kelvin probe gas sensing setup. The ammonia gas at $30 \mathrm{ppm}$ concentration (ammonia-air mixture) was introduced into the test chamber and changes in CPD between PANI film and

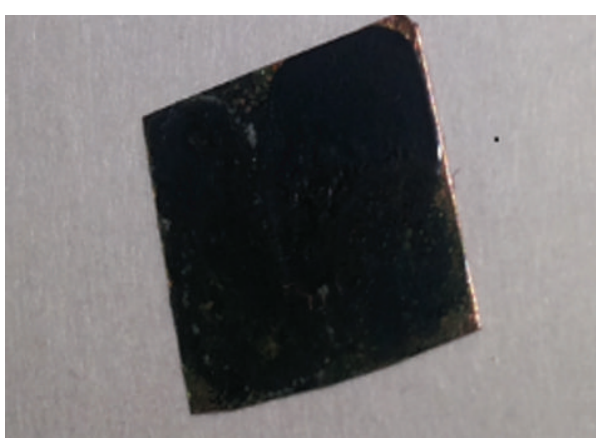

Figure 1: Spin coated PANI-DBSA layer over copper substrate.

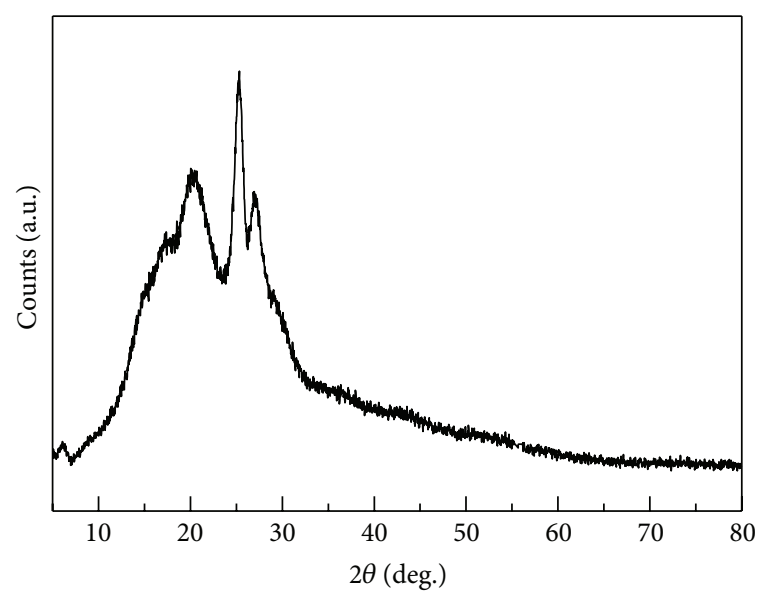

FiguRE 2: XRD pattern of PANI-DBSA powder.

$\mathrm{Cu}$ substrate were recorded after every second using a data acquisition system.

\section{Results and Discussions}

2.1. X-Ray Diffraction Measurement. Figure 2 shows the XRD pattern of DBSA-PANI powder that displays three distinguished peaks at $2 \theta$ values of $20.5^{\circ}(d=4.32 \AA)$, $25.2^{\circ}(d=3.52 \AA)$, and $26.9^{\circ}(3.31 \AA)$. In particular, the existence of $\sim 20^{\circ}$ and $\sim 25^{\circ}$ peaks (which represent periodicity parallel and perpendicular to chain axis, resp.) confirms the formation of PANI. Further, the relative prominence of $25^{\circ}$ peak confirms the existence of PANI in its highly doped (electrically conducting) ES form, which is expected to show good sensitivity towards basic gases like ammonia.

2.2. UV-Visible Spectroscopy. Figure 3 shows the UV-visible absorption spectra of PANI-DBSA dispersion in chloroform. The spectrum consists of three distinguished transitions centred on $346 \mathrm{~nm}$ (band-1), $431 \mathrm{~nm}$ (band-2), and $732 \mathrm{~nm}$ (band-3) wavelengths $[23,25]$. Band-1 corresponds to $\pi \rightarrow$ $\pi^{*}$ transition of the benzenoid rings whereas band-2 and band- 3 are attributed to polaron $\rightarrow \pi^{*}$ and $\pi^{*} \rightarrow$ polaronic transitions, respectively. The prominence of band-3 compared to band-1 shows that PANI is formed in its doped ES form. Exposure to basic gases like ammonia causes 


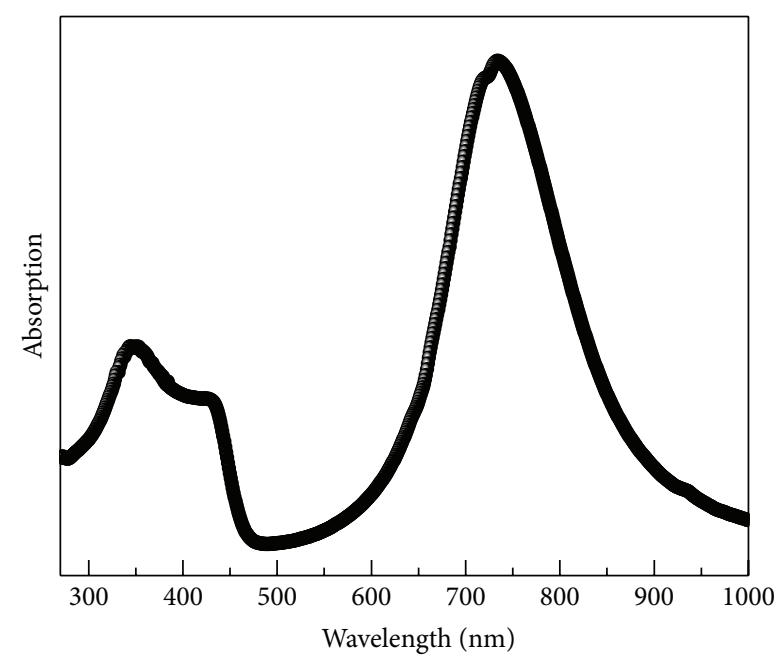

FIgURE 3: UV-visible spectra of PANI-DBSA dispersion in chloroform.

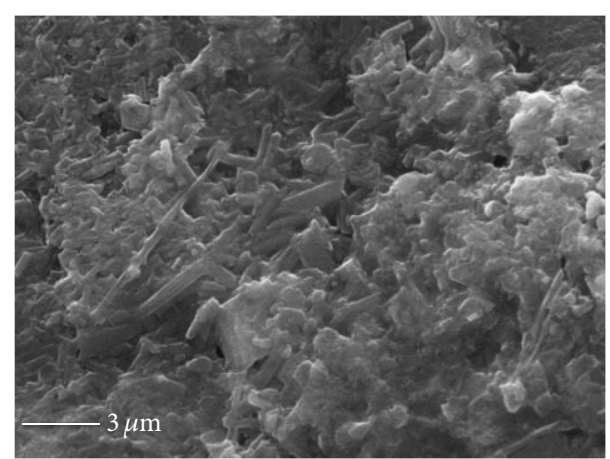

Figure 4: SEM image of PANI-DBSA powder.

partial undoping (shift towards emeraldine base, i.e., EB form) leading to systematic variation of relative intensity and position of these bands, which forms the basis of optical sensors. Interestingly, the undoping also leads to change in work function (WF) of PANI, such that $\mathrm{WF}_{\mathrm{ES}}>\mathrm{WF}_{\mathrm{EB}}$. Therefore, we exploited Kelvin probe technique to trace gas induced variation of WF difference between PANI-DBSA layer and $\mathrm{Cu}$ substrate.

2.3. Morphological Investigations. The SEM image of synthesized PANI-DBSA particles is shown in Figure 4 and it can be seen that the formed PANI-DBSA particles display rod-like structure with $\sim 0.2 \mu \mathrm{m}$ diameter and $\sim 1 \mu \mathrm{m}$ length. The decrease in particle size leads to increase in surface-tovolume ratio, thereby exposing more sites for interactions with incident gas. Further, the elongated particles are known to display improved charge transport. These factors are expected to improve gas sensing response.

\subsection{Ammonia Sensing via Kelvin Probe Gas Sensing Setup.} The Kelvin probe technique measures the change in work function $(W F)$ in terms of change in contact potential $(\Delta C P)$ between the sample and reference electrode (gold tip) and not

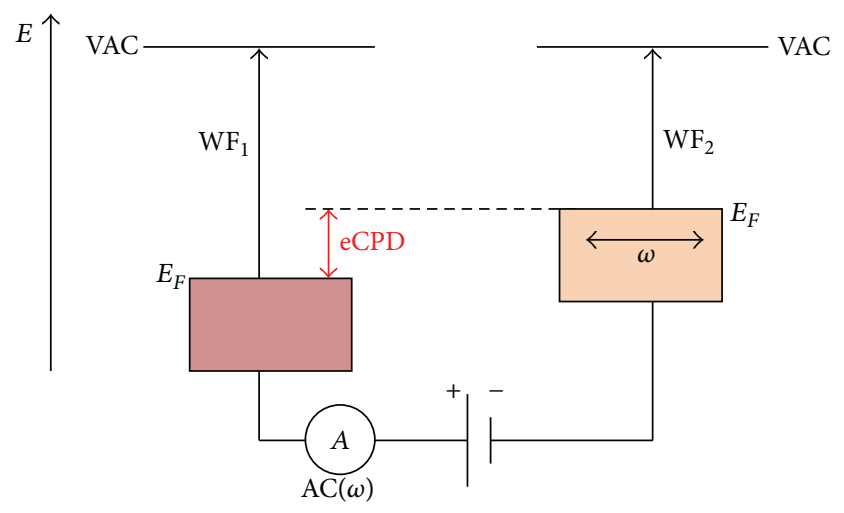

FIGURE 5: Schematic representation of Kelvin probe measurement principle.

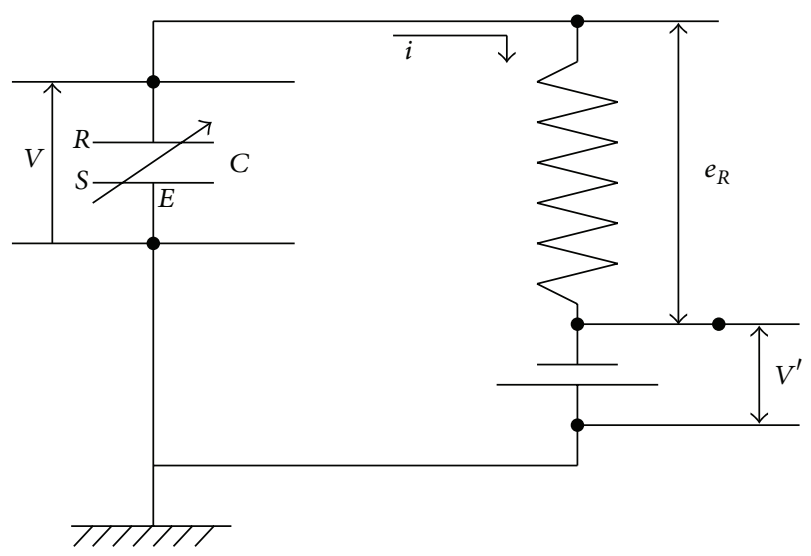

FIgURE 6: Circuit diagram of Kelvin probe measurement setup.

as the absolute work function values [26]. Figure 5 shows the contact potential difference that corresponds to change in WF of material with respect to reference electrode.

The CPD measurement is based on the vibrating capacitor of Kelvin-Zisman [27] which is shown schematically in Figure 6.

Here, a capacitor is constituted by two electrodes; the first one is the sample mounted onto a piezoelectric ceramic that work as an active electrode $(S)$, whereas the other one is a gold tip based reference electrode $(R)$. This capacitor with inherent capacitance $C$ tends to charge under the influence of natural contact potential difference $(V)$ so that the developed charge $(Q)$ can be expressed as

$$
Q=C V
$$

When the piezoelectric ceramic is polarized, the sample $(S)$ is subjected to lateral vibration, leading to the periodic change of the capacitance, which in turn induces a pseudosinusoidal modulated current $(i)$ in the circuit. This current produces an alternating voltage drop $\left(e_{R}\right)$ across an external resistor which is amplified via lock-in amplifier into a direct voltage $E$ which is the direct measure of the CPD change under the test gas. In the beginning, a counter potential $V^{\prime}$ 


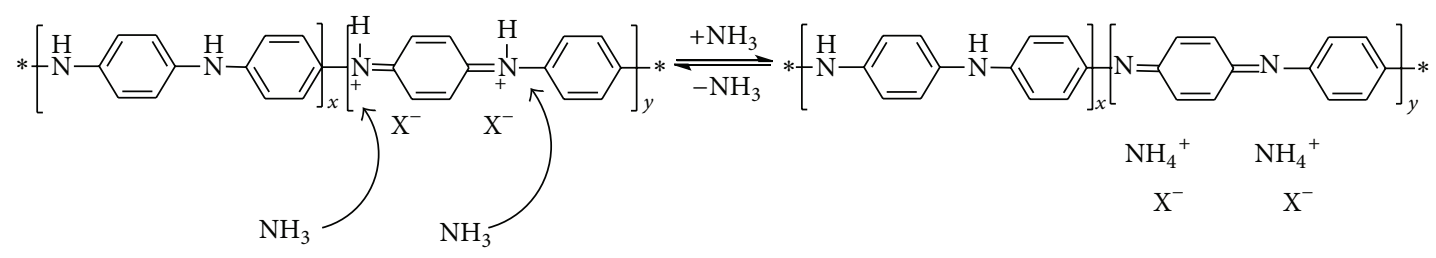

$\mathrm{X}^{-}=$DBSA Anion

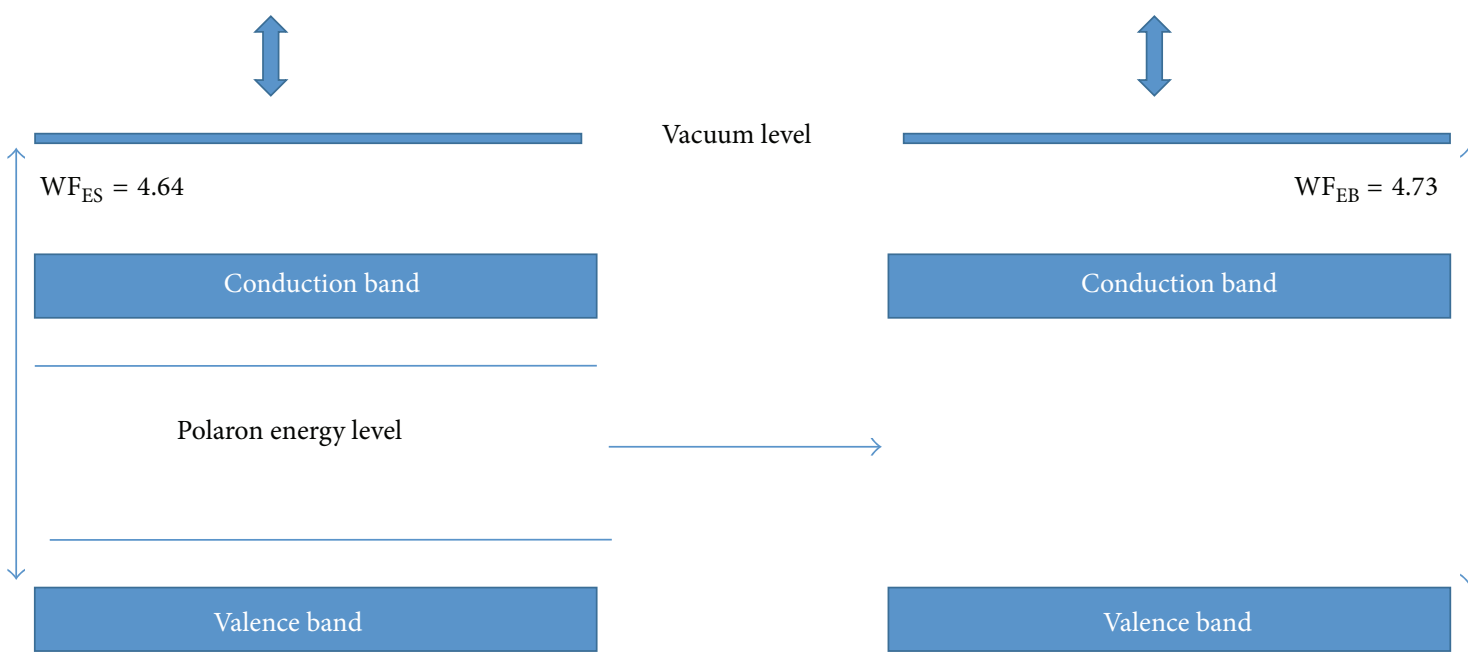

FIGURE 7: Schematic representation of the ammonia mediated undoping of PANI-DBSA layer (top) and change in work function (bottom).

is manually adjusted to cancel the initial CPD to a zero value under the dilution gas.

Gas sensing via Kelvin probe involves the measurement of variation of CPD versus time for a given test gas concentration [28]. When layer of DBSA doped PANI (ES) deposited over $\mathrm{Cu}$ substrate is exposed to ammonia, partial undoping converts the ES toward emeraldine base (EB) form. As already discussed earlier, such deprotonation induced undoping is accompanied by change in work function of the PANI-DBSA layer (shown schematically in Figure 7).

Figure 8 shows sensing response of PANI-DBSA/Cu substrate sensing element at room temperature upon exposure to $30 \mathrm{ppm}$ gas concentration. Before exposure to ammonia, the CPD was $+0.05951 \mathrm{~V}$. However, after exposure to ammonia gas (30 ppm), CPD showed an abrupt decrease followed by exponential change to attain a saturation value of $-0.032227 \mathrm{~V}$.

This can be ascribed to the sorption of ammonia gas molecules on the surface of sensing DBSA-PANI layer leading to deprotonation and change in oxidation level, which tends to increase the work function.

During the recovery stage, when ammonia supply was stopped and dry air was passed through the system, ammonia desorption takes place, leading to restoration of doped state and original oxidation level. These changes we observed in terms of initial fast rise of CPD value followed by long exponential rise part. The response and recovery time value were $329 \mathrm{sec}$ and $3600 \mathrm{sec}$, respectively. The sensitivity of

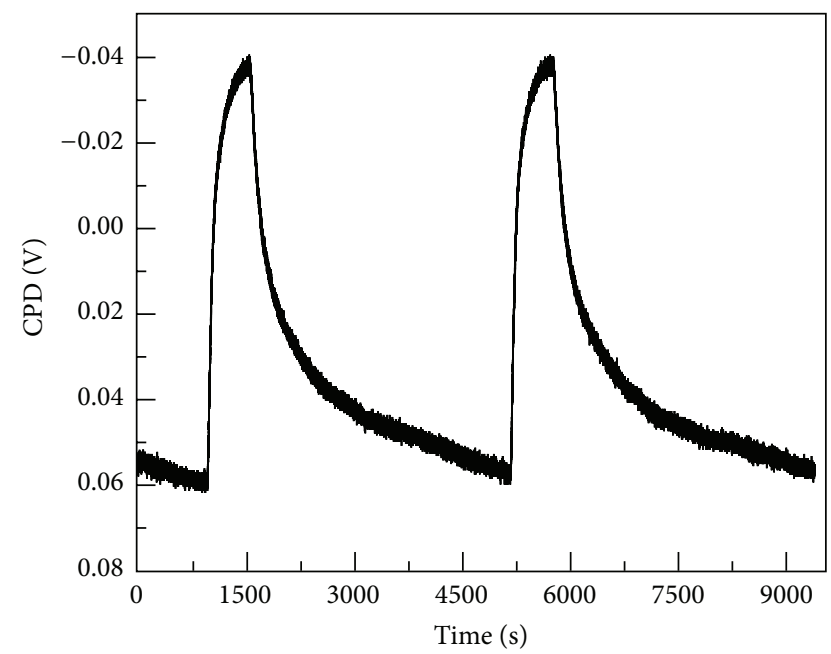

FIgURE 8: Repeatability curve of PANI-DBSA nanostructured film towards $30 \mathrm{ppm}$ of ammonia.

the sensor toward ammonia can be expressed in terms of $\mathrm{CPD}$ values in the presence and absence of gas as

$$
\text { Sensitivity }=\frac{\left(\mathrm{CPD}_{\text {Ammonia }}-\mathrm{CPD}_{\text {Dry Air }}\right)}{\mathrm{CPD}_{\text {Dry Air }}} \text {. }
$$

On the basis of CPD variation, the sensor's sensitivity for $30 \mathrm{ppm}$ ammonia is found to be 1.54 . In order to observe 
the reversibility and repeatability, the sensor was subjected to two sensing cycles (involving ammonia exposure, saturation, and recovery steps), keeping ammonia concentration at $30 \mathrm{ppm}$ for each cycle. It was observed that, in the second cycle, response and recovery times and sensitivity values were almost the same as in the case of the first cycle. This demonstrates the good repeatability of the sensor which is extremely important for accurate detection and quantification of ammonia. Nevertheless, we feel that the CPD based sensor is a relatively new concept and modifications are expected in terms of active material designing, film forming techniques, active layer's morphology, and selection of substrate, so that sensor's response/recovery time as well as sensitivity can be further improved.

\section{Conclusion}

Submicron rod shaped particles of DBSA doped PANI have been synthesized by oxidative polymerization and coated onto copper substrate from chloroform solution. The PANI/Cu system is exposed to known ammonia concentration and its CPD is monitored over the time via Kelvin probe technique. The prepared gas sensor rapidly and reversibly detects up to $30 \mathrm{ppm}$ ammonia gas at room temperature conditions. The sensor displayed response time of $329 \mathrm{sec}$, recovery time of $3600 \mathrm{sec}$, and sensitivity value of 1.54 with good repeatability. Nanostructuring of PANI, modulation of film morphology and thickness, and formation of nanocomposites are expected to further improve the sensing characteristics of such sensors.

\section{Conflict of Interests}

The authors declare that there is no conflict of interests regarding the publication of this paper.

\section{Acknowledgments}

The authors wish to thank Director, CSIR-NPL, for according permission to publish the work. The authors also thank Dr. N. Vijayan for XRD patterns and Mr. K. N. Sood for SEM images. They are also thankful to Director, CEERI, for extending Kelvin probe facility. Anju Yadav is thankful to CSIR for the award of SRF.

\section{References}

[1] http://en.wikipedia.org/wiki/Ammonia.

[2] M. Tajkarimi, H. P. Riemann, M. N. Hajmeer, E. L. Gomez, V. Razavilar, and D. O. Cliver, "Ammonia disinfection of animal feeds-laboratory study," International Journal of Food Microbiology, vol. 122, no. 1-2, pp. 23-28, 2008.

[3] http://www.nytimes.com/2009/10/04/health/04meat.html?pagewanted $=$ all\&_r $=0$.

[4] http://www.washingtonpost.com/national/health-science/anhydrous-ammonia-fertilizer-abundant-important-hazardous/2013/ 04/18/c2d4c69c-a85a-1le2-a8e2-5b98cb59187f_story.html.

[5] "Van nostrand reinhold," Environmental Science \& Technology, vol. 18, no. 4, p. 105A, 1984.
[6] B. Timmer, W. Olthuis, and A. van den Berg, "Ammonia sensors and their applications-a review," Sensors and Actuators B: Chemical, vol. 107, no. 2, pp. 666-677, 2005.

[7] P. Saini, Ed., Fundamentals of Conjugated Polymer Blends, Copolymers and Composites: Synthesis, Properties and Applications, John Wiley \& Sons, New York, NY, USA, 2015.

[8] R. Gosangi and R. Gutierrez-Osuna, "Active temperature modulation of metal-oxide sensors for quantitative analysis of gas mixtures," Sensors and Actuators B: Chemical, vol. 185, pp. 201210, 2013.

[9] N. Bârsan and U. Weimar, "Understanding the fundamental principles of metal oxide based gas sensors; the example of $\mathrm{CO}$ sensing with $\mathrm{SnO}_{2}$ sensors in the presence of humidity," Journal of Physics: Condensed Matter, vol. 15, no. 20, pp. R813-R839, 2003.

[10] J. Janata and M. Josowicz, "Conducting polymers in electronic chemical sensors," Nature Materials, vol. 2, no. 1, pp. 19-24, 2003.

[11] H. Bai and G. Shi, "Gas sensors based on conducting polymers," Sensors, vol. 7, no. 3, pp. 267-307, 2007.

[12] J. Kumar, M. Shahabuddin, A. Singh et al., "Highly sensitive chemo-resistive ammonia sensor based on dodecyl benzene sulfonic acid doped polyaniline thin film," Science of Advanced Materials, vol. 7, no. 3, pp. 518-525, 2015.

[13] P. Saini, T. Kuila, S. Saha, and N. C. Murmu, "15. Graphene and its nanocomposites for gas sensing applications," in Advanced Sensor and Detection Materials, A. Tiwari and M. M. Demir, Eds., pp. 467-500, John Wiley \& Sons, 2014.

[14] H. S. Nalwa, Handbook of Organic Conductive Molecules and Polymers, Wiley, 1997.

[15] U. Lange, N. V. Roznyatovskaya, and V. M. Mirsky, "Conducting polymers in chemical sensors and arrays," Analytica Chimica Acta, vol. 614, no. 1, pp. 1-26, 2008.

[16] K. C. Persaud, "Polymers for chemical sensing," Materials Today, vol. 8, no. 4, pp. 38-44, 2005.

[17] T. K. Das and S. Prusty, "Review on conducting polymers and their applications," Polymer-Plastics Technology and Engineering, vol. 51, no. 14, pp. 1487-1500, 2012.

[18] S. Mikhaylov, N. Ogurtsov, Y. Noskov et al., "Ammonia/amine electronic gas sensors based on hybrid polyaniline- $\mathrm{TiO}_{2}$ nanocomposites. The effects of titania and the surface active doping acid," RSC Advances, vol. 5, no. 26, pp. 20218-20226, 2015.

[19] S. Bhadra, D. Khastgir, N. K. Singha, and J. H. Lee, "Progress in preparation, processing and applications of polyaniline," Progress in Polymer Science, vol. 34, no. 8, pp. 783-810, 2009.

[20] J. Huang, S. Virji, B. H. Weiller, and R. B. Kaner, "Nanostructured polyaniline sensors," Chemistry - A European Journal, vol. 10, no. 6, pp. 1314-1319, 2004.

[21] D. Then, A. Vidic, and C. Ziegler, "A highly sensitive selfoscillating cantilever array for the quantitative and qualitative analysis of organic vapor mixtures," Sensors and Actuators B: Chemical, vol. 117, no. 1, pp. 1-9, 2006.

[22] C. M. Hangarter, M. Bangar, A. Mulchandani, and N. V. Myung, "Conducting polymer nanowires for chemiresistive and FETbased bio/chemical sensors," Journal of Materials Chemistry, vol. 20, no. 16, pp. 3131-3140, 2010.

[23] P. Saini and M. Arora, "Formation mechanism, electronic properties \& microwave shielding by nano-structured polyanilines prepared by template free route using surfactant dopants," Journal of Materials Chemistry A, vol. 1, no. 31, pp. 8926-8934, 2013. 
[24] P. Saini, R. Jalan, and S. K. Dhawan, "Synthesis and characterization of processable polyaniline doped with novel dopant NaSIPA," Journal of Applied Polymer Science, vol. 108, no. 3, pp. 1437-1446, 2008.

[25] R. Taş, M. Can, and S. Sönmezoğlu, "Preparation and characterization of polyaniline microrods synthesized by using dodecylbenzene sulfonic acid and periodic acid," Turkish Journal of Chemistry, vol. 39, no. 3, pp. 589-599, 2015.

[26] J. Abad and J. Colchero, "Metal-conducting polymer interface studied by Kelvin probe microscopy: Au and Al on poly(3-octylthiophene)," Journal of Polymer Science. Part B: Polymer Physics, vol. 52, no. 16, pp. 1083-1093, 2014.

[27] E. Souteynard, D. Nicolas, and J. R. Martin, "Semiconductor/metal/gas behaviour through surface-potential change," Sensors and Actuators B: Chemical, vol. 25, no. 1-3, pp. 871-875, 1995.

[28] D. Nicolas, E. Souteyrand, and J.-R. Martin, "Gas sensor characterization through both contact potential difference and photopotential measurements," Sensors and Actuators B: Chemical, vol. 44, no. 1-3, pp. 507-511, 1997. 

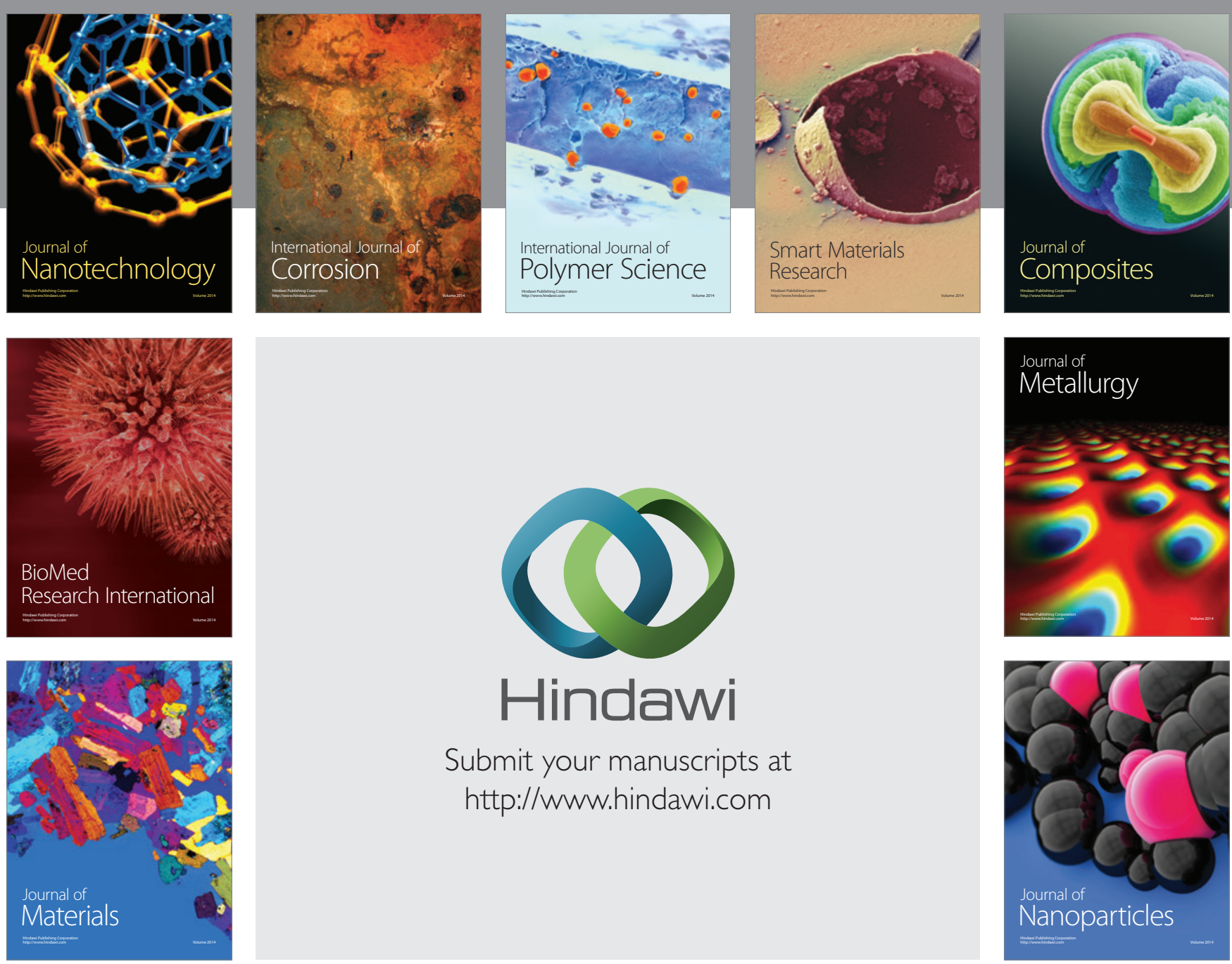

Submit your manuscripts at http://www.hindawi.com
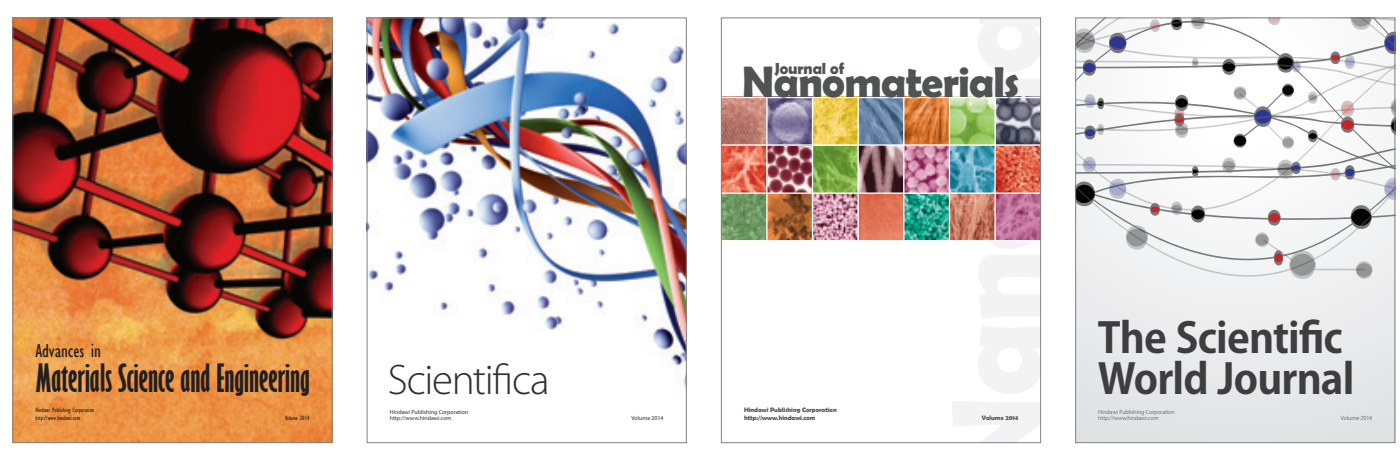

\section{The Scientific World Journal}
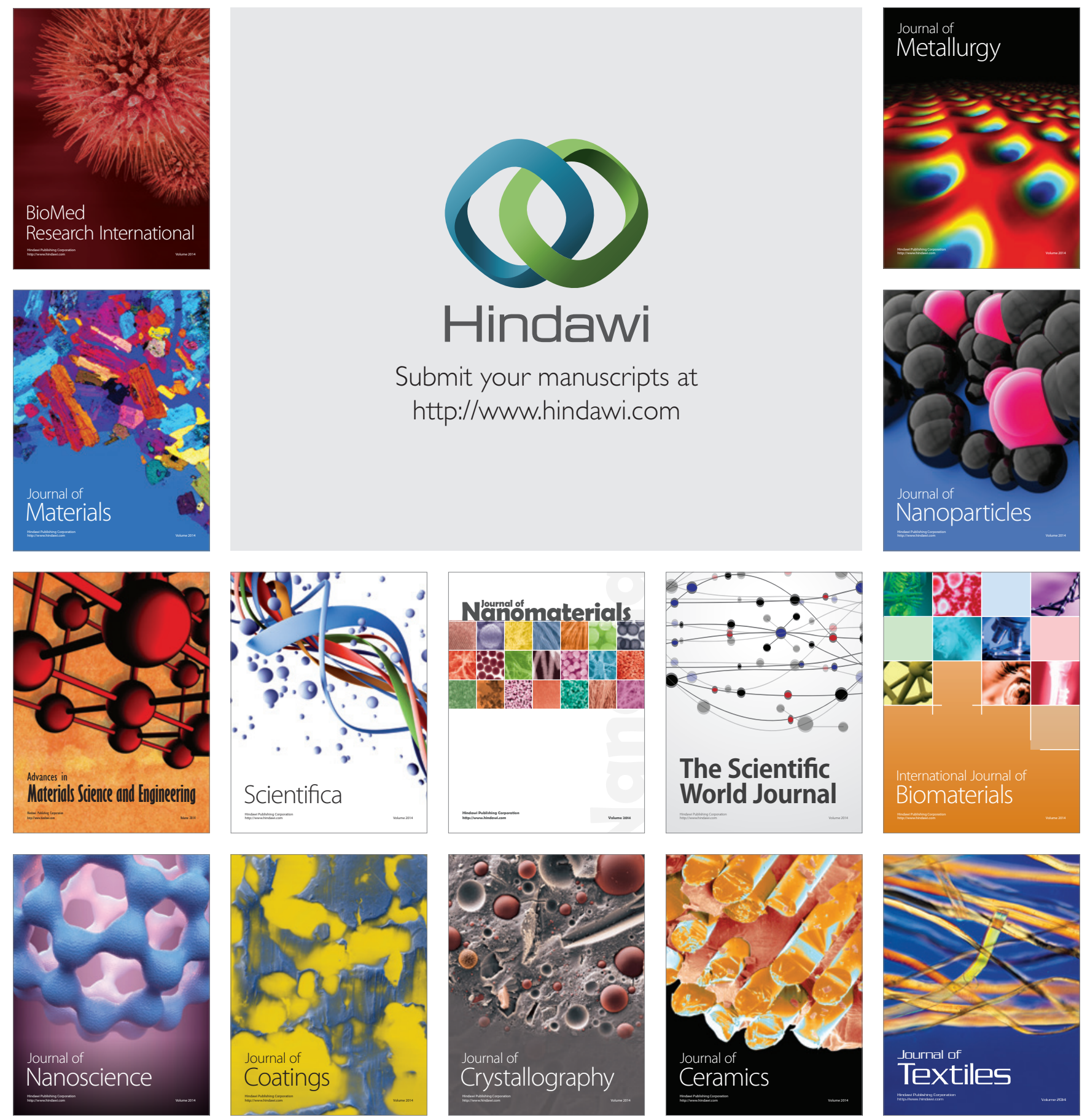